\section{Visual perception during phacoemulsification cataract surgery under subtenons anaesthesia}

SS Wickremasinghe, PG Tranos, N Sinclair, PS Andreou, ML Harris and BC Little

Eye (2003) 17, 501-505. doi:10.1038/

sj.eye. 6700414

Keywords: subtenons; phacoemulsification; visual experience; anxiety; counselling

\section{Introduction}

It is well documented that the vast majority of patients undergoing cataract surgery under topical or regional blocks experience intraoperative visual phenomena. ${ }^{1-3}$

Although patient consent for cataract surgery usually involves extensive technical information about their preoperative and postoperative management, the intraoperative experience has received less attention. Since intraoperative perception is a most vivid and feared event for many patients, preoperative counselling should include information about visual perception during the procedure.

Subtenons anaesthesia as described by Hansen et $a l^{4}$ and by Stevens ${ }^{5}$ is becoming increasingly popular since it provides satisfactory anaesthesia and analgesia without the risks associated with insertion of sharp needles into the retro- or periorbital space.

We conducted the first to our knowledge survey assessing patient visual experience during phacoemulsification and intraocular lens implantation using subtenon's blocks. Our study attempts to describe the spectrum and the intensity of visual phenomena observed by those patients, as intraoperative visual impression can be a significant determinant of patient satisfaction.

Patients and methods

In all, 104 patients underwent phacoemulsification and posterior chamber
Department of Ophthalmology Royal Free Hospital

Pond Street

London NW3 2QG, UK

Correspondence: $S$ Wickremasinghe Broomfield Hospital Court Road Chelmsford CM1 7ET, UK Tel: + 441245491149 E-mail: sanjeewa_w@ hotmail.com

Received: 30 April 2002 Accepted: 7 October 2002

None of the authors has a financial or proprietary in any material or method mentioned 
intraocular lens implantation under subtenons anaesthesia at a London Teaching Hospital. Patients included in the study all had age-related cataract without coexisting ocular pathology and all had preoperative visual acuities of at least count fingers at $1 \mathrm{~m}$. No patient eluded to a history of colour vision defects nor did any admit to any psychiatric illness. All patients included had uneventful surgery, with 'in the bag' implantation of the lens implant. Patients with posterior capsule rupture, with or without vitreous loss were excluded, as were those requiring corneal sutures.

Cataracts were graded using the Lens Opacities Classification System III (LOCS III), a system based on a set of standard colour photographic transparencies of nuclear opalescence (NO), nuclear colour (NC), cortical cataract $(\mathrm{C})$ and posterior subcapsular cataract $(\mathrm{P})$ that can be used as references to classify lens opacities at the slit lamp or in standardised lens photographs. The scale for nuclear colour and nuclear opacities ranges between 0.1 and 6 units, whereas for the cortical and posterior subcapsular cataract ranges between 0.1 and 5 units.

Only patients with a score between 6 and 12 units in the operated eye were recruited for the study. This was done to ensure a relatively homogenous group of patients with broadly similar lens opacities, to allow for later comparison of individual visual experiences.

Patients were recruited consecutively regardless of whether or not the fellow eye had undergone cataract surgery, but only one eye of any patient was included. The case mix and the surgeons involved were representative of the routine clinical practice of the unit. Ethics committee approval was not required for this study.

Prior to surgery, the technique of anaesthesia and surgical details were explained to all patients. The operated eye was dilated with $1 \%$ cyclopentolate (Chauvin Pharmaceuticals Ltd, Essex, UK) and 2.5\% phenylephrine drops (Chauvin Pharmaceuticals Ltd).

In the anaesthetic room, patients had proxymetacaine (Chauvin Pharmaceuticals Ltd) applied topically before the insertion of an eyelid speculum. The conjunctiva and the tenons capsule were dissected. An amount of $2 \%$ lignocaine was instilled into the subtenons space via a subtenons cannula. Following administration of the anaesthetic, the patients were taken into theatre and draped with an opaque plastic sheet, so that only the operated eye was exposed. None of the patients received additional analgaesia or sedation. Surgery was performed using an operating microscope (Carl Zeiss, Germany) set at a standard illumination.

Patients underwent phacoemulsification of the lens via a $3.2 \mathrm{~mm}$ superocorneal incision using 'divide and conquer' technique. Aspiration of the soft lens matter was achieved by using a bimanual technique. A Foldable lens, Ceeon (Pharmacia Ltd, NJ, USA), was placed into the capsular bag following enlargement of the corneal section. On completion of surgery, patients were given subconjuctival, cefuroxime (GlaxoSmithKline, Uxbridge, UK) and betnesol (Medeva, Speke, UK).

Between $30 \mathrm{~min}$ to $2 \mathrm{~h}$ after surgery, theatre staff administered a standard questionnaire (Appendix 1), while the patients were in the recovery area. Staff administering the questionnaire had no knowledge of the type of anaesthesia the patients had received.

The patients were not informed of the questionnaire preoperatively, and there was no discussion about the possible visual sensations during surgery.

The questionnaire focused on peroperative visual phenomena the patient may have noticed. Movement, colours, flashes, instruments, fingers or face of surgeon and light intensity were 'seen' or 'not seen'. Subjective experience of photophobia and an overall assessment as to whether the visual experiences were frightening were also enquired about.

With regard to movements and light intensity, subgroups were assigned according to the extent to which each was experienced.

\section{Statistical analysis}

Statistical analysis of the data was carried out using SPSS version 9 (SPSS Inc, Chicago. IL, USA). $\chi^{2}$ and Fisher's exact tests (two-tail) were used to evaluate the noncontinuous data.

\section{Results}

The visual experiences during phacoemulsification were assessed in 104 patients. Of the total number of patients, there were $38(36.5 \%)$ males and $66(63.5 \%)$ females. The age range varied from 48 to 90 years. The mean $( \pm S D)$ age of patients was $74.0 \pm 8.8$ years (males $72.0 \pm 9.5$ and females $76.0 \pm 8.0$ years). The mean lens opacity grade (LOCS) was 6.9 \pm 0.9 .

In total, $75.6 \%$ patients had not had prior cataract surgery. The average duration of operation (from instillation of anaesthetic to removal of drape) was 30.6 $( \pm 9.8) \mathrm{min}$. The mean volume of anaesthetic used was $4.64 \pm 0.98 \mathrm{ml}$. Although not documented as a visual analogue scale, none of the study patients complained of significant intraoperative pain.

In all, $12.5 \%$ of patients saw no light during the procedure, while $87.5 \%$ of patients claimed that they saw at least some light. Of those seeing light, 51.0\% revealed that they perceived bright light, whereas the other $36.5 \%$ saw dim light intraoperatively. In all, $11.5 \%$ of patients experienced a change in brightness of the operating microscope light during the procedure, and 56.7\% 
patients disclosed that they had seen coloured lights during surgery. The perception of movement during surgery was completely absent in most patients $(64.4 \%)$, while $28.8 \%$ saw some and $6.7 \%$ revealed that they had seen significant amounts.

The majority of patients did not see any surgical instruments, the surgeon's fingers or face $(90.4,87.5$ and $95.2 \%$, respectively).

Most patients experienced no untoward symptoms during surgery with only $9.6 \%$ experiencing photophobia and $13.5 \%$ finding the visual experience frightening. Of the patients who experienced photophobia, although the actual numbers only made up a small percentage of subjects, there was a significant association, $P=0.002$, with age. Younger patients ( $<65$ years) experienced higher levels $(5.9 \%)$ than older patients $(2.9 \%, 65-79$ years and $1.0 \%, 80+$ ). There was no association between sex, previous cataract surgery, volume of anaesthetic, length of procedure and the type of visual symptoms described.

The factors affecting patients overall assessment as to whether the visual experience was frightening or not are summarised in Table 1. Although most visual phenomena did not cause distress, some events were associated with higher levels of anxiety than would be expected. The events associated with a statistically significant increase in the level of anxiety were the perception of colours, $P=0.005$, volumes of anaesthetic less than $4 \mathrm{ml}, P=0.003$ and photophobia, $P=0.003$. These associations are illustrated graphically in Figures 1-3. No significant associations were noted with the age of patients, sex, previous cataract surgery, degree of lens opacity or other visual phenomena.

\section{Discussion}

The visual experience of patients during cataract surgery performed with different types of local or topical anaesthesia has been recorded in the past. It has been speculated that the images seen by patients intraoperatively may represent a combination of coloured entopic phenomena, light-induced visual sensation and afterimages. ${ }^{6}$

Levin and $\mathrm{O}^{\prime}$ Connor ${ }^{7}$ reported that all of their 26 patients who had been assessed for intraoperative visual perception had reduced visual acuity after retrobulbar anaesthesia, while movements of the instruments during surgery was described by $73 \%$ of these patients.

Similarly, Brent and Singh ${ }^{8}$ reported that $86 \%$ of 30 consecutive patients who received retrobulbar block had diminished visual acuity. More recently Au Eong et $a l^{9}$ in two different papers investigated the visual experience of 70 patients undergoing phacoemulsification and 100 patients undergoing extracapsular cataract extraction using retrobulbar injection. No light perception during
Table 1

\begin{tabular}{|c|c|c|c|}
\hline & $\begin{array}{c}\text { Percentage } \\
\text { finding visual } \\
\text { experience } \\
\text { frightening } \\
(\%)\end{array}$ & $\begin{array}{l}\text { Percentage not } \\
\text { finding visual } \\
\text { experience } \\
\text { frightening } \\
(\%)\end{array}$ & $\begin{array}{c}\text { Significance } \\
(\mathrm{P})\end{array}$ \\
\hline \multicolumn{4}{|l|}{ Age } \\
\hline$<65$ & 35.7 & 15.9 & $0.170^{\mathrm{a}}$ \\
\hline $65-79$ & 42.9 & 45.5 & \\
\hline $80+$ & 21.4 & 38.6 & \\
\hline \multicolumn{4}{|l|}{ Sex } \\
\hline Male & 35.7 & 36.7 & $1.000^{\mathrm{a}}$ \\
\hline Female & 64.3 & 63.3 & \\
\hline \multicolumn{4}{|c|}{ Prior surgery } \\
\hline Yes & 72.7 & 76.1 & $1.000^{\mathrm{a}}$ \\
\hline No & 27.3 & 23.9 & \\
\hline \multicolumn{4}{|c|}{ LOCSIII score } \\
\hline$<6.5$ & 62.1 & 59.7 & $0.642^{\mathrm{a}}$ \\
\hline$>6.5$ & 37.9 & 40.3 & \\
\hline \multicolumn{4}{|c|}{ Volume of anaesthetic } \\
\hline$\leq 4 \mathrm{ml}$ & 90.9 & 41.9 & $0.003^{* b}$ \\
\hline$>4 \mathrm{ml}$ & 9.1 & 58.1 & \\
\hline \multicolumn{4}{|l|}{ Length } \\
\hline$<30 \mathrm{~min}$ & 37.5 & 38.5 & $1.000^{\mathrm{a}}$ \\
\hline$>30 \mathrm{~min}$ & 62.5 & 61.5 & \\
\hline \multicolumn{4}{|l|}{ Movement } \\
\hline Yes & 50 & 66.7 & $0.340^{\mathrm{a}}$ \\
\hline No & 50 & 33.3 & \\
\hline \multicolumn{4}{|l|}{ Flashes } \\
\hline Yes & 28.6 & 32.2 & $1.000^{\mathrm{b}}$ \\
\hline No & 71.4 & 67.8 & \\
\hline \multicolumn{4}{|l|}{ Colours } \\
\hline Yes & 100 & 50 & $0.005^{* a}$ \\
\hline No & 0 & 50 & \\
\hline \multicolumn{4}{|l|}{ Instruments } \\
\hline Yes & 21.4 & 7.8 & $0.132^{\mathrm{b}}$ \\
\hline No & 78.6 & 92.2 & \\
\hline \multicolumn{4}{|l|}{ Fingers } \\
\hline Yes & 0 & 12.2 & $0.687^{\mathrm{b}}$ \\
\hline No & 100 & 87.8 & \\
\hline \multicolumn{4}{|l|}{ Faces } \\
\hline Yes & 0 & 5.6 & $1.000^{\mathrm{b}}$ \\
\hline No & 100 & 94.4 & \\
\hline \multicolumn{4}{|l|}{ Light } \\
\hline Yes & 0 & 14.4 & $0.163^{\mathrm{a}}$ \\
\hline No & 100 & 85.6 & \\
\hline \multicolumn{4}{|l|}{ Photophobia } \\
\hline Yes & 28.6 & 6.7 & $0.028^{* b}$ \\
\hline No & 71.4 & 93.3 & \\
\hline
\end{tabular}




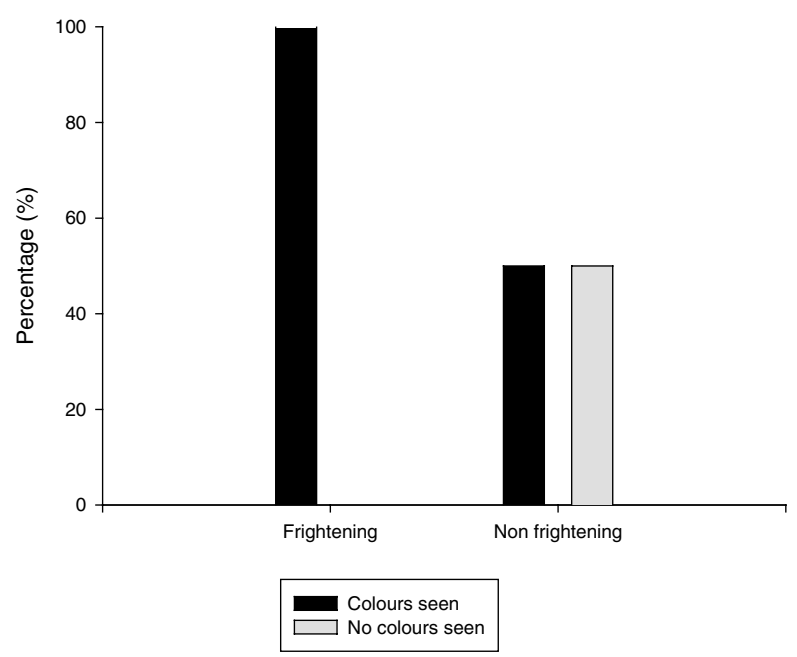

Figure 1 Effect of the perception of colours on the visual experience being interpreted as being frightening.

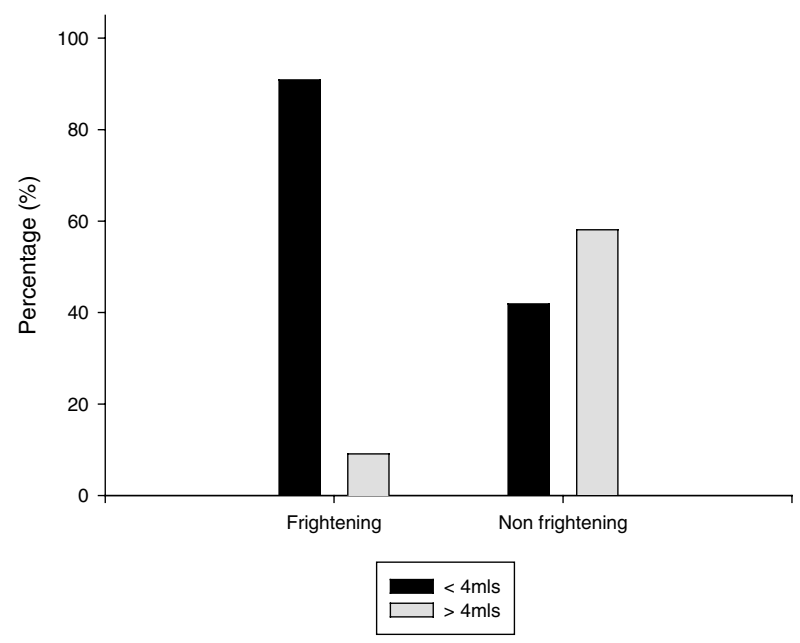

Figure 2 Effect of anaesthetic volume on the finding of the visual experience as frightening.

surgery was reported by 15.7 and $20 \%$ of these patients, respectively. The rest described 1 or more colours (55.7 and $56 \%)$, movements (48.6 and 39\%), instruments (17.1 and $16 \%)$, and the surgeon's fingers or hands (15.7 and 10\%).

Talks $e a^{1}{ }^{1}$ reported that all 20 patients given peribulbar anaesthesia had a reduction in visual acuity with $25 \%$ of them losing light perception during surgery. None of the patients observed operating instruments, but $20 \%$ perceived abstract visual images. ${ }^{1}$

Some aspects of visual awareness during phacoemulsification under topical anaesthesia have also been described in two other studies. In one study, all patients reported that they could see at least some light during the surgery, $96.2 \%$ of patients could also see one or more colours and $61.5 \%$ observed movements. ${ }^{10}$ In the other study, colours were observed by 73 of 102 patients, while the remaining 29 patients were only aware of white illumination. Movement and surgical instruments were seen by 19 and 12 patients, respectively. ${ }^{3}$

Our study is the first attempt to investigate systematically subjective visual perception during phacoemulsification surgery under subtenons anaesthesia. Visual awareness was present in $87.5 \%$ of the patients who saw at least some light with the operated eye during the procedure. In all, $56.7 \%$ patients disclosed that they had observed coloured lights during surgery, but only a small minority reported visualising surgical instruments, the surgeon's fingers or face (9.6, 12.5 and $4.8 \%$, respectively). Moreover, $9.6 \%$ experienced photophobia and $13.5 \%$ described the visual impression as frightening. Although not statistically significant, younger subjects ( $<65$ years) tended to find the visual experience more frightening than those over 80 years (35.7 vs 21.4\%). This increased level of anxiety may be due in part to the fact that younger individuals generally have less in the way of lens opacity, but may also be because of a greater level of awareness of the situation. The less dense cataracts may also explain the heightened level of photophobia disclosed by those below 65 years.

The observation that colour perception was associated with a frightening visual experience suggests that vivid intraoperative visual phenomena are more likely to result in patient's psychological distress. The authors speculate that the intraoperative corneal distortion, the periodic instillation of balanced salt solution (BSS) on the corneal surface and the intermittent intracameral irrigation during phacoemulsification result in variable dispersion of the operating microscope light, generating multicolour visual phenomena.

Furthermore, the correlation between lower volume of anaesthetic and frightening visual perception indicates that employment of larger amounts of anaesthetic produces more effective reduction of visual function. This can be the result of either a direct anaesthetic effect to the optic nerve or can be secondary to the mechanical optic nerve compression by the anaesthetic injected into the subtenon's space. ${ }^{11-13}$

Other postulations regarding the mechanisms responsible for the decline of vision during cataract surgery include the transient elevation of intraocular pressure, which may occur during sealing of cataract wound. This can potentially result in retinal ischaemia and subsequent reduction of vision. ${ }^{14}$ Finally, the rapid bleaching of the retinal photoreceptors attributable to the bright illumination from the operating microscope light may also account for the compromised visual awareness. ${ }^{3}$

Comparison of our results with prior studies on visual perception is difficult because of the differing nature of anaesthesia. Nevertheless, our results are largely consistent with previously reported findings,,$^{1,3,7,9,11}$ in 


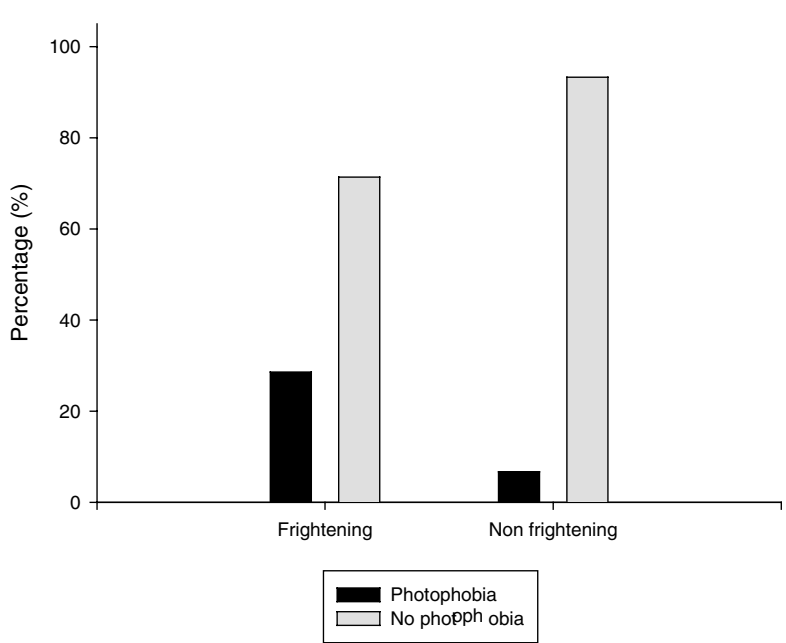

Figure 3 Effect of photophobia on the perception of the visual experience being interpreted as frightening.

that despite variable intraoperative reduction of vision, patients continue to experience visual phenomena.

Potential confounding variables include the anxiety level of patients' and their perception of pain during the peroperative period (although none of the patients admitted to significant discomfort). These may constitute a significant determinant in the patient's visual awareness and consequently their overall visual impression.

Furthermore, a variable length of time between the implementation of the anaesthetic block and the initiation of the operation may have had an impact on visual impression predominantly affecting the early stages of the procedure. Lastly, we recognise the potential limitations in the study because of its non-controlled nature.

Many patients admit to some apprehension about the possibility of visualising images of their cataract surgery. Additionally, $9.1 \%$ of patients in our study found surgery to be frightening as a result of their visual experiences. The experience may be perceived as being frightening because patients may not be expecting to see these visual sensations.

In order to alleviate some of this anxiety, a detailed explanation of possible visual phenomena (particularly bright light and colours) that may be encountered should be explained to all (but especially younger patients) preoperatively.

\section{References}

1 Talks SJ, Chong NH, Gibson JM, Francis IR. Visual acuity and pupillary reactions after peribulbar anaesthesia. $\mathrm{Br} J$ Ophthalmol 1994; 78(1): 41-43.

2 Au Eong KG, Lee HM, Lim AT, Voon AT, Yong VS. Subjective visual experience during extracapsular cataract extraction and intraocular lens implantation under retrobulbar anaesthesia. Eye 1999; 13(Part 3a): 325-328.
3 Newman DK. Visual experience during phacoemulsification cataract surgery under topical anaesthesia. $\mathrm{Br} J$ Ophthalmol 2000; 84(1): 13-15.

4 Hansen EA, Mein CE, Mazzoli R. Ocular anesthesia for cataract surgery: a direct sub-Tenon's approach. Ophthalmic Surg 1990; 21(10): 696-699.

5 Stevens JD. A new local anaesthesia technique for cataract extraction by one quadrant sub-Tenon's infiltration. $\mathrm{Br} J$ Ophthalmol 1992; 76: 670-674.

6 Sumich PM, Francis IC, Kappagoda MB, Alexander SL. Artist's impression of endocapsular phacoemulsification surgery. J Cataract Refract Surg 1998; 24(11): 1525-1528.

7 Levin ML, O'Connor PS. Visual acuity after retrobulbar anesthesia. Ann Ophthalmol 1989; 21(9): 337-339.

8 Brent BD, Singh H. The effect of retrobulbar anesthesia on visual acuity in planned extracapsular cataract extraction. Ophthalmic Surg 1991; 22(7): 392-395.

9 Au Eong KG, Lim TH, Lee HM, Yong VS. Subjective visual experience during phacoemulsification and intraocular lens implantation using retrobulbar anesthesia. J Cataract Refract Surg 2000; 26(6): 842-846.

10 Au Eong KG, Low CH, Heng WJ, Aung T, Lim TH, Ho SH, Yong VS. Subjective visual experience during phacoemulsification and intraocular lens implantation under topical anesthesia. Ophthalmology 2000; 107(2): 248-250.

11 Ropo A, Ruusuvaara P, Setala K. Visual evoked potentials after retrobulbar or periocular anaesthesia. $\mathrm{Br} J$ Ophthalmol 1992; 76(9): 541-544.

12 Verma L, Arora R, Kumar A. Temporary conduction block of optic nerve after retrobulbar anesthesia. Ophthalmic Surg 1990; 21(2): 109-112.

13 Arora R, Verma L, Kumar A, Kunte R. Peribulbar anesthesia and optic nerve conduction. J Cataract Refract Surg 1991; 17(4): 506-508.

14 Steinert RF, Oster JG, Francis JM. Postoperative retinal ischemia with self-sealing cataract surgery incisions. Am J Ophthalmol 1997; 123(1): 124-125.

\section{Appendix 1}

General patient details

Name

D.O.B

Sex

1st/2nd eye

Lens opacities grade

Anaesthetic details

Volume of anaesthetic

Peroperative Visual

phenomena

Length of surgery

Movements

Flashes

Colours

Instruments

Fingers

Face

Light

Photophobia

Frightening visual

experience

Intraoperative pain

$\begin{array}{llll}\begin{array}{l}\text { None } \\ \text { Yes }\end{array} & \text { Little (+) } & & \text { Lot }(++) \\ \begin{array}{l}\text { Specify } \\ \text { Yes }\end{array} & & \text { No } & \\ \text { Yes } & & & \\ \text { Yes } & & \text { No } & \\ \text { None } & \text { Dim } & \text { No } & \\ \text { Yes } & & \text { No } & \\ \text { Yes } & & \text { No } & \text { Bright } \\ & & \text { No } & \\ \text { Yes } & & & \\ & & & \\ & & & \\ & & & \end{array}$

